\title{
Fauna and Flora of the Inner and Outer Hebrides King's College (University of Durham) Biological Expeditions
}

By Prof. J. W. Heslop Harrison, F.R.S.

SO long ago as 1934, the idea of exploring the $S$ Hebrides with the view of writing a comprehensive Flora of the Inner and Outer Isles was conceived by the Department of Botany, King's College, University of Durham, and with it, as a corollary, the notion of studying the evolution of local races in the same area. At the same time,

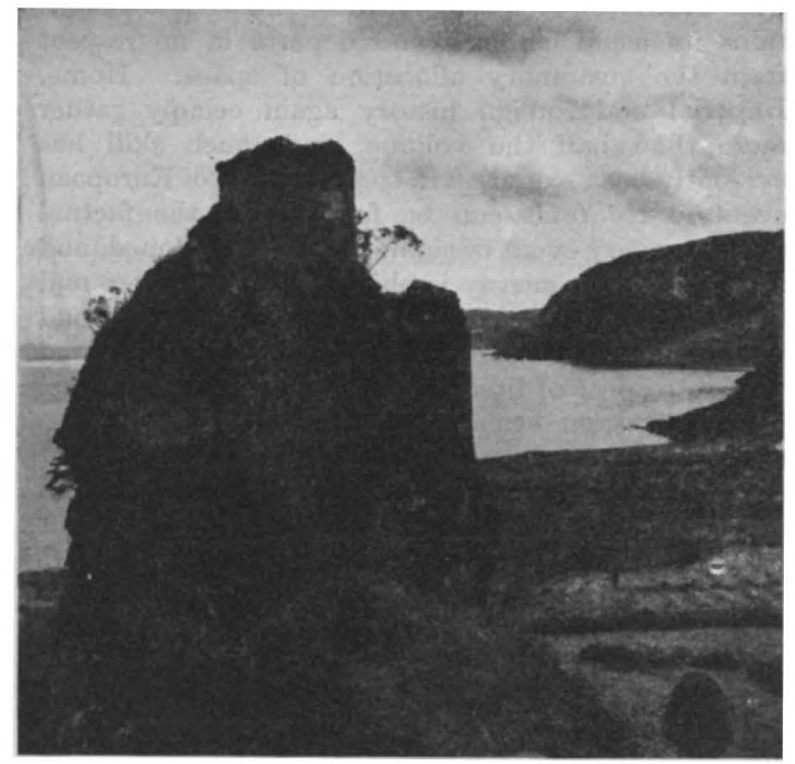

Volcanic vent with Brochel Castle, Isle of RaAsay; CLIFFS AT SCREAPADAL BEHIND.

too, the whole of the plans necessary for bringing our project to a successful conclusion were formulated.

In consequence, since our first visit to Raasay in 1934, a yearly average of eleven weeks, spread over various parts of the year, has been spent in working the islands. Thus, in 1935 we visited Skye, Raasay, Scalpay, Longay, Mull, Coll, Tiree, Barra, South Uist, Canna and Sanday; in 1936 Skye, Raasay, Scalpay, South Rona, Eigg, Canna and Sanday ; in 1937, Skye, Soay, Raasay, Pabbay, Coll, Rhum, Eigg, Canna, Sanday, Barra, Berneray and Mingulay; and, finally, in 1938, Rhum, Eigg, Muck, Eilean nan Each, Hyskeir, Lewis, Harris, Taransay, North Uist, Baleshare, the Monach Islands, South Uist and Eriskay. From this it will be seen that our investigations, although incomplete, have covered most of the area to be explored, and that we are in a position to take stock of our present results, and to assess the value of our work.

Almost at the very commencement of our researches, we encountered a remarkable and inspiring cliff flora growing upon the precipitous cliffs, towering a thousand feet above the sea, along the east coast of Raasay. This included not only plants of alpine predilections such as Arabis petraea, Silene acaulis, Dryas octopetala, Oxyria digyna, Polygonum viviparum, but, in addition, commoner plants such as Geum urbanum, Lychnis dioica, Geranium lucidum, Calamagrostis Epigeios, so rare and local in, or formerly considered absent from, the islands. There, too, jutting out from the cliffs, the rare shrub Sorbus rupicola flourished. Moreover, elsewhere in Raasay, we encountered unexpected species in the form of Juncus pygmaeus, J. capitatus and Cicendia pusilla, the first-named hitherto only recorded in Britain from the Lizard, the second from the same district and Anglesey, and C. pusilla from the Channel Islands.

These discoveries naturally invited speculation as to the causes of the peculiar and discontinuous distribution of the plants concerned. At once, it was forced upon us that the problem and its solution depended upon the Pleistocene and early Holocene history and geography of the Hebrides. Similarly, the resemblance between the positions of the plants on Raasay and those so brilliantly studied by Fernald in Newfoundland and in the Gaspé Peninsula, Quebec, was too striking to be disregarded. Naturally, we concluded that the circumstances explaining the situation in one case accounted for it in the other. These, in Fernald's opinion, and in ours, lay in the view that many, if not all, of the species involved, had escaped, by virtue of their positions, or by the local failure of glaciation, the wholesale extermination due to ice action so often pictured for us by those of extreme views.

Thus we were compelled to add to the original items of our programme a study of the influence of Pleistocene glaciations upon the composition and distribution of the Hebridean flora and fauna. To aid in this, a new line of attack, involving tedious examination of the pollen contents of the various peat deposits available, was of necessity developed.

Later, as we passed from island to island, these 
convictions have been progressively strengthened. The Isles of Eigg and Canna, with the flora of their magnificent western cliffs, reproduce on a smaller scale the conditions of Raasay, whilst the Isle of Rhum, with its rugged mountain masses, yields much more weighty evidence. On the latter island, the American grass, Festuca prolifera, reported by Fernald from Newfoundland, Anticosti, Gaspé and New Hampshire, turned up. Further, the Alpine penny cress, Thlaspi calaminare, formerly supposed to be restricted in Britain to Derbyshire, was collected freely on Fionchra and on the seaward cliffs of Bloodstone Hill. In the same way, the southern mountain massif produced the Norwegian sandwort, Arenaria norvegica, once listed as occurring with us only in the Shetlands and in Sutherland. Other significant plants secured on the Isle of Rhum included Carex atrofusca, Deschampsia alpina, Juncus capitatus, Filago gallica and many others, generally possessing alpine habitats.

When we passed to the Outer Islands, the same tale was continued. There the plant novelties belonged more particularly to two groups: (1) those of western or south-western tendencies; (2) those of arctic or alpine preferences. The former are exemplified by Carum verticillatum and Vicia Orobus and the latter by Alopecurus alpinus, Festuca prolifera, Carex Halleri, C. rariflora, C. rupestris, etc. Here, more especially in the case of South Uist, the case for glacial survival becomes much more powerful, for the Hecla-Beinn Mhor mountain group reveals considerable areas free from evidences of glaciation. The presence of Alopecurus alpinus adds a fact of vital importance, for the grass does not appear on the continent of Europe at all.

On the animal side, although few groups have been ignored, our chief interests have lain in the Mollusca, Insecta and Arachnida-circumstances determined by the personnel of the various expeditions. Among the molluses, our principal discoveries were the detection of the American species Planorbis dilatata on Raasay, and of Clausilia cravenensis on North Uist and Harris, both again suggesting that the species are glacial relicts.

In the Insecta our most striking captures have been among the aquatic Coleoptera. These included Hydroporus foveolatus, hitherto only known from high mountain lakes in the Alps and Pyrenees, and now taken in similar localities in the central mountains of Rhum, Deronectes canariensis, a Canary Island species, now recorded from Barra, and the Mediterranean Aulonogyrus striatus from Raasay. Again, the import of the evidence seems unmistakable.

Among the Lepidoptera, although some of our additions to the Hebridean lists were to be expected, others stand out conspicuously; these are species like Omphaloscelis lunosa, Pachnobia leucographa, Miana expolita, Selidosema ericetaria, $Z$ ygaena achilleae and Z. purpuralis. At this stage, one of our special quests, Nyssia zonaria, a moth possessing apterous females, needs strong emphasis. In the form of the local race atlantica (Heslop Harrison), we took it on Canna, Sanday, Rhum, Muck, Coll, Tiree, Harris, North and South Uist, Baleshare, Taransay, Monach Islands, Eriskay, Barra and Mingulay-a very significant and informative series of islands.

The Hymenoptera, likewise, have their quota of evidence to supply In this connexion we would

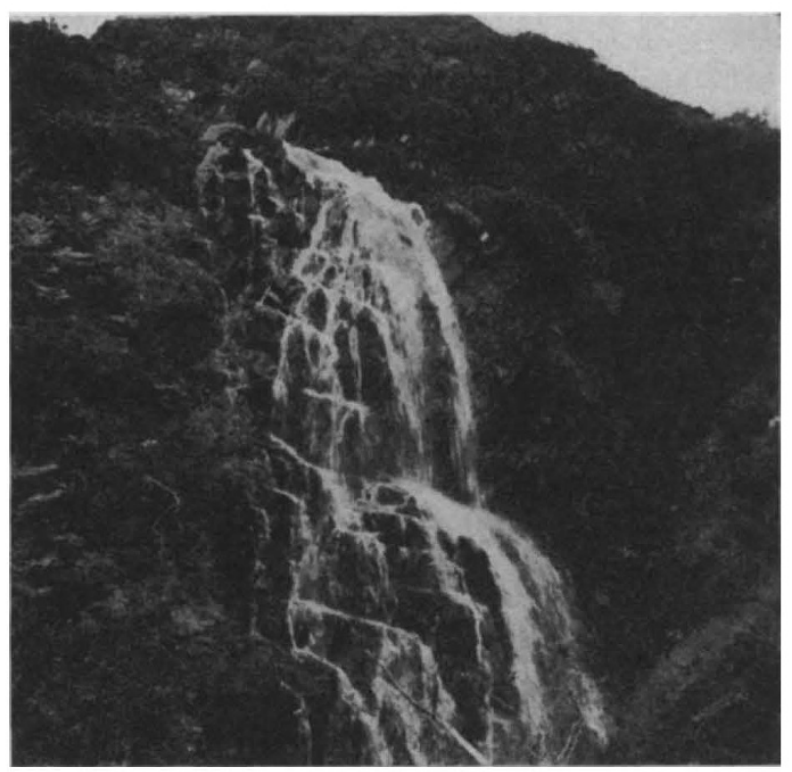

Waterfall on Allt liath, Islf of Scalpay, with Osmunda regalis (ROYAL FERN).

single out as specially instructive the two Bombi, Bombus smithianus and B. jonellus var. hebridensis. The former we encountered on the same islands as Nyssia zonaria, with Eigg, Hyskeir, Berneray, and Raasay, in addition, whilst the latter was captured on every member of the Outer Island group examined.

On the other hand, in the case of the Hemiptera, although they provided unexpectedly long lists, only one species needs comment and that is Anthocoris pilosus Jak., beaten from trees on Scalpay; it is new to the British Fauna.

The Arachnida simply continue the indications of the other arthropods ; in particular, the southern element represented by the spiders Drassodes pubescens, Zelotes latreillii, Z. apricorum and Xysticus pini deserves mention.

It is impossible within the limits of the present article to set out the whole of the results, or the 
deductions to be made from them ; that remains for our final reports. Nevertheless, a few facts may be offered now, and a few deductions mentioned without providing full details of the arguments leading up to them. In the first place, referring to our original task of producing a Flora and Fauna of the Inner and Outer Hebrides, it can be reported that we collected no fewer than 639 forms of flowering plants and their closest

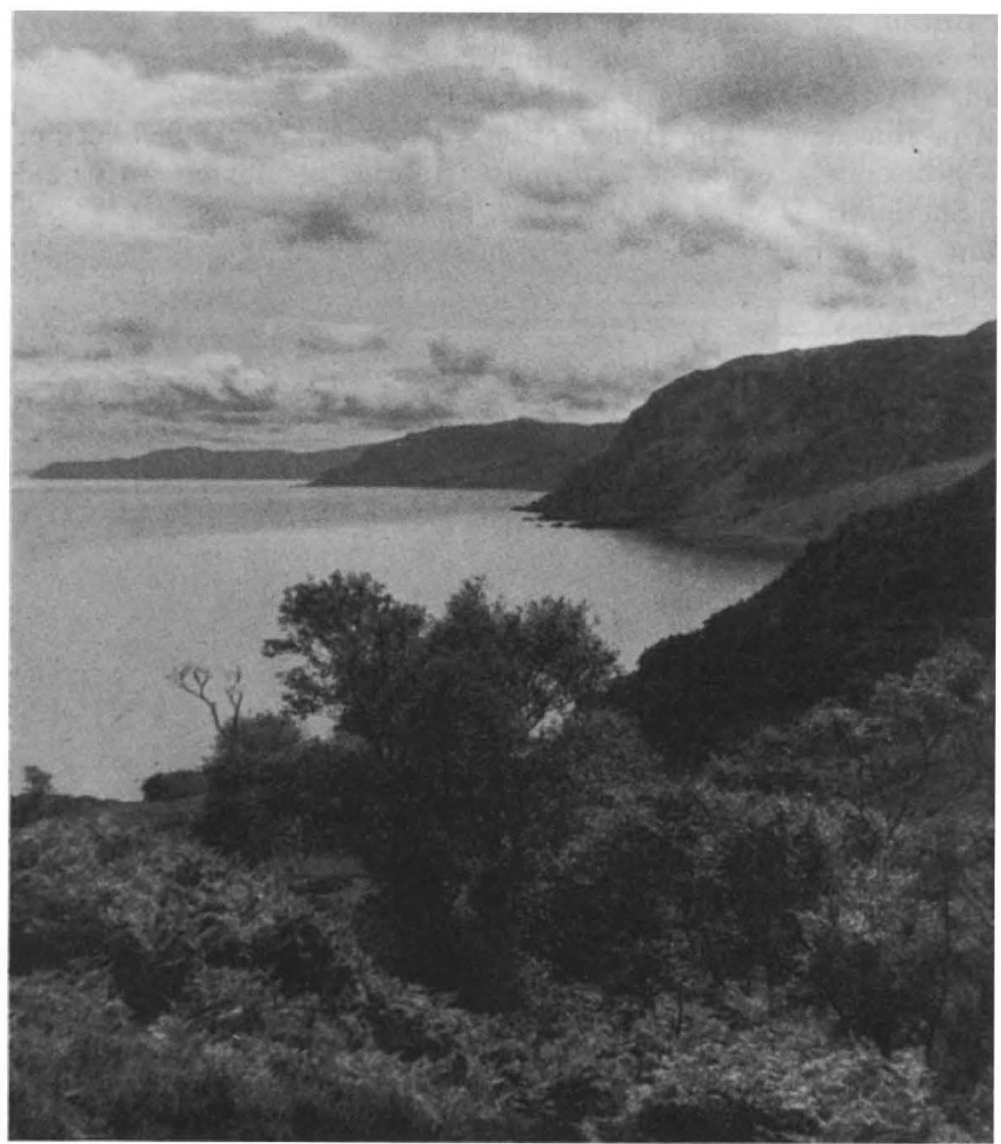

East coast of RaAsay, Inner Hebrides. concluded that at least some of the plants observed have survived the Ice Age, both in the Inner and Outer Islands, in habitats in, or near, those where they now exist.

Further, taking due cognizance of the whole of the animals and plants, we have been forced to admit that present geographical divisions do not harmonize with those based in biogeographical facts. From the faunistic and floristic points of view, Skye, Raasay, Scalpay, South Rona and Soay belong undoubtedly to the mainland; no form is more emphatic in deciding this than the endemic rose, Rosa Sherardi var. glabrata (Ley) Heslop Harrison. On the other hand, in the same respects, Canna, Sanday, Rhum, Eigg, Muck, Hyskeir, Tiree and Coll, just as emphatically line up with the Outer Isles.

In turn, this points to a longcontinued separation of the islands just named from the mainland, and their more or less recent connexion with the 'Long' Island. In leading to this conclusion, no evidence has been of greater value than the distribution of Nyssia zonaria var. atlantica and Bombus smithianus, coupled with the indications of the Hyskeir reef peats, as well as of the occurrence of the bluebell, tormentil, etc., of the common blue butterfly, Polyommatus icarus, and of the small dragonfly Ischnura elegans on the same islet. Both the Hyskeir peat, and its present flora and fauna, suggest very recent oscillations and subsidences indeed, as do the submarine peats west of Uist.

At this point also, we should make it clear that we have been driven to allies from the islands lying to the north of Skye, 651 from the Rhum, Eigg, Canna group to the south thereof, and approximately 600 from the Outer Islands. Of these at least 150 are new county records. We see little scope for adding further to these lists in the case of Watsonian Vice-county 104, but we are certain that, judging from our last year's results in the Outer Hebrides, our 1939 work will add substantially to those from Vice-county 110.

Our results in the insect groups discussed above and in others, as well as in the molluscs, arachnids, birds, mammals, etc., are of the same order.

Now let us consider the remaining aspects of our work. As will have been made abundantly clear from various remarks made above, we have conclude that such forms as Nyssia zonaria var. atlantica and Bombus smithianus, which display a so-called fringing distribution, do not supply, as is generally supposed, the extreme western limits of species driven in that direction by invaders from the east. On the contrary, we regard them as the present limits of species falling back eastward as the land (the "Tir-fo-thonn" of Gaelic legend) sank beneath the waves, or was fretted away by Atlantic storms. In these cases we believe that they survived the glacial period in lands far to the west of the limits of to-day. Link this up with the presence of the same insects in the western islands of Ireland, and it will be seen that the land connexion between Ireland and Scotland, and the date of its severance, become part of the same problem, and that its 
solution is assisted by the presence of the moths Zygaena purpuralis and Miana expolita in the west of Ireland, and in Rhum. Moreover, the distribution of the two bees Bombus smithianus and $B$. jonellus var. hebridensis hints that the Shetland Islands cannot be neglected in the same discussion.

In our evolutionary studies, we have been struck by the unusual facies presented by many island species of animals and plants when they are studied alongside representatives of ordinary English populations, and we have already described well-marked island races, for example, an Outer Island honeysuckle Lonicera Periclymenum var. Clarki, a new race of Nyssia zonaria and so on, the whole emphasizing the importance both of the local race, and of isolation, in evolution. From the very nature of this work, observation must be backed by experimental work, and this, in the case of some forms, is well in hand.

\section{Photochemical Reactions in the Gaseous, Liquid and Solid States*}

\section{By Dr. C. F. Goodeve, University College, London}

DHOTOCHEMISTRY is concerned with processes in which light quanta are absorbed and chemical changes result. A molecular species is characterized by a certain spatial arrangement of atoms governed by forces due to electrons. The oscillating electric field of a light quantum acts on a binding electron and raises it to an energy-level where the bond is either loosened or broken. This permits the spatial rearrangements to take place which we observe as chemical change.

The photochemical process may be divided into two stages: the primary process which occurs more or less simultaneously with the absorption process, and the secondary process which occurs consequent to the first. These two processes can be studied separately and by different methods, the first by a study of the absorption spectrum and the second by the methods of reaction kinetics.

\section{Photosensitivity}

The dual nature of photochemistry is emphasized by a consideration of the velocity of photochemical reactions. This velocity generally follows the equation

$$
-\frac{d n}{d t}=\gamma I_{a}
$$

where $n$ represents the number of molecules of absorbing species present at any moment, $-\frac{d n}{d t}$ their rate of decrease with time, and $I_{a}$ the absorbed light intensity in quanta per second. $\gamma$ is the quantum efficiency defined as

$$
\frac{\text { No. of molecules changed }}{\text { No. of quanta absorbed }} \text {. }
$$

* Taken from a course of afternoon lectures given at the Royal Institution, February 16, 23, March 2. References to, and further details of, most of the work described here may be found in papers chemistry ( $J$. Phys. Chem. June 1938), and recent papers by Bowen, by Norrish and by the author, each with collaborators.
If a beam of monochromatic light of intensity $I$ quanta per second falls on a thin layer of absorbing substance the concentration of which is $n / v$ molecules per c.c., the fraction of the light absorbed is proportional to the concentration and to the thickness, and is given by

$$
\frac{I_{a}}{I}=\alpha \cdot \frac{n}{v} \cdot l
$$

The constant of proportionality $\alpha$ is the molecular extinction coefficient and has a value usually between $10^{-16}$ and $10^{-22} \mathrm{~cm} .{ }^{2}$. It is the 'target area' that a molecule presents to the light beam, that is, the chance of it absorbing light.

We can combine equations (1) and (2) to give us the final equation for the rate of a photochemical change

$$
-\frac{d n}{n d t}=\alpha \gamma \frac{I l}{v}=\alpha \gamma \cdot \frac{I}{A},
$$

where $I / A$ is the intensity per unit area. This is the simplest equation for the rate of a photochemical reaction, and it is to be noted that the rate-determining constant is the product $\alpha \gamma$. This combined quantity is obviously the photosensitivity.

We see therefore that the sensitivity of a substance to light is governed by two quantities : the chance of the substance absorbing a light quantum, and the efficiency of the process per quantum absorbed. For example, the well-known reaction which takes place when a mixture of chlorine and hydrogen is illuminated is a very fast one. The extinction coefficient of chlorine is comparatively low-about $10^{-21} \mathrm{~cm} .{ }^{2}$. This low extinction is, however, counterbalanced by the fact that the quantum efficiency in the reaction with hydrogen is very high, between $10^{3}$ and $10^{5}$. The photosensitivity therefore has values from $10^{-18}$ to $10^{-16} \mathrm{~cm} .^{2}$ per quantum absorbed. It follows from equation (3) that in bright daylight, the blue light 